\section{Breeding sites of bluetongue vectors in northern Europe}

SIR, - Bluetongue has recently been spreading in northern Europe, starting in Belgium and the Netherlands in August 2006. In 2006 there were 695 outbreaks in Belgium (399 sheep farms and 296 cattle farms). In 2007, according to data provided by the Federal Agency for the Safety of the Food Chain (www.afsca.be), 6598 Belgian farms were affected (4187 cattle farms, 2398 sheep farms and 13 goat farms).

The midges responsible for the transmission of bluetongue virus (BTV) belong to the genus Culicoides. However, only a few species of this genus seem to act as a biological vector.

Sound vector control methods require thorough knowledge of the physiology, biology and ecology of all developmental stages of the vector(s). The nature of the breeding sites of most biting midges is poorly known. Therefore, a study was planned that would examine all constituent biotopes of what can be considered a typical outbreak site for the presence of Culicoides larvae and nymphs.

The study was carried out in a farm in Grand-Manil, Belgium (50 $33^{\prime} 19^{\prime \prime} \mathrm{N}$, $4^{\circ} 41^{\prime} 06^{\prime \prime}$ E) between March and July 2007. The farm surroundings and the neighbouring fields or pastures were sampled three times during that period. On each occasion one litre soil samples of different biotopes were collected and then subjected to two techniques: a technique for extracting larvae using a saturated magnesium sulphate solution (direct flotation); and an incubation method at $24^{\circ} \mathrm{C}$ to allow adults to emerge. These two approaches were applied to samples of 43 different biotopes. The number of immature stages, assessed by the first technique, and the species identification of emerged adults made possible by the second technique, demonstrated the general preference of the larvae for the top layer of permanently non-submerged humid environments and more importantly revealed the larval microhabitats of the species considered to be potential vectors of BTV.

It was observed that the species of the complex Culicoides obsoletus/scoticus, whose larval habitat is still unknown and whose role in the transmission of BTV has recently been established (Mehlhorn and others 2007), are abundant in maize silage residues: 238 and $40 \mathrm{C}$ obsoletus adults emerged from two substrate samples col- lected in mid-March and the end of April, respectively. Both of those samples also harboured 15 C scoticus adults.

Other species that may have vectorial competence also prefer anthropogenic environments linked to livestock farming. Indeed, Culicoides dewulfi and Culicoides chiopterus are commonly found overwintering in cattle dung. From the substrate samples taken in mid-March, 82 $C$ dewulfi and $133 C$ chiopterus adults were recovered.

In conclusion, the results of this study show that the breeding sites of some major bluetongue vector species are found mainly in anthropic environments, close to farms. In the future, we will focus on the detection of other larval sites close to farms in order to plan an effective control strategy against bluetongue vectors.

Jean-Yves Zimmer, Eric Haubruge, Frédéric Francis, Jeannine Bortels, Gregory Simonon, Gembloux

Agricultural University, B-5030 Gembloux, Belgium

Bertrand Losson, Bernard Mignon, Julien Paternostre, Faculty of

Veterinary Medicine, University of Liège, B-4000 Liège, Belgium

Redgi De Deken, Gill De Deken,

Isra Deblauwe, Maxime Madder Prince Leopold Institute of Tropical Medicine, Department of Animal Health, B-2000 Antwerp, Belgium

\section{Christiane Fassotte, Ruddy}

Cors, Thibault Defrance, Walloon Agricultural Research Centre, Department of Biological Control and Plant Genetic Resources, B-5030 Gembloux, Belgium

\section{Reference}

MEHLHORN, H., WALLDORF, V., KLIMPEL, S., JAHN, B., JAEGER, F., ESCHWEILER, J., HOFFMANN, B. \& BEER, M. (2007) First occurrence of Culicoides obsoletus-transmitted bluetongue virus epidemic in central Europe. Parasitology Research 101, 219-228 